\title{
BMJ Open Autologous haematopoietic stem cell transplantation following high-dose chemotherapy for non-rhabdomyosarcoma soft tissue sarcomas: a Cochrane systematic review*
}

\author{
Frank Peinemann, ${ }^{1}$ Alexander M Labeit ${ }^{2}$
}

To cite: Peinemann F, Labeit AM. Autologous haematopoietic stem cell transplantation following high-dose chemotherapy for non-rhabdomyosarcoma soft tissue sarcomas: a Cochrane systematic review*. BMJ Open 2014;4:e005033. doi:10.1136/bmjopen-2014005033

- Prepublication history for this paper is available online. To view these files please visit the journal online (http://dx.doi.org/10.1136/ bmjopen-2014-005033)

Received 10 February 2014 Revised 26 June 2014 Accepted 14 July 2014

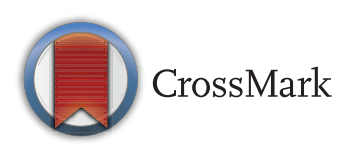

${ }^{1}$ Children's Hospital, University of Cologne, Cologne, Germany ${ }^{2}$ Center for Outcomes Research, University of Illinois College of Medicine at Peoria, Peoria, Illinois, USA

Correspondence to Frank Peinemann; pubmedprjournal@gmail.com

\section{ABSTRACT}

Objectives: We conducted a systematic review to compare the efficacy and adverse events of autologous haematopoietic stem cell transplantation (HSCT) following high-dose chemotherapy (HDCT) versus standard-dose chemotherapy (SDCT) in patients with locally advanced or metastatic non-rhabdomyosarcoma soft tissue sarcomas (NRSTS).

Setting: Patients were observed in hospital units specialised for cancer therapy.

Participants: The review evaluated 294 patients with 19 different subtypes of malignant NRSTS. The patients had a median age between 10 and 46 years (range 2-65) and were mostly men.

Primary and secondary outcome measure: The planned and measured primary outcomes were overall survival and treatment-related mortality. The planned and measured secondary outcomes were progressionfree survival, grade 3-4 non-haematological toxicity and secondary neoplasia. Other secondary outcomes including disease-free survival, event-free survival and health-related quality of life were not reported.

Results: We included 62 studies reporting on 294 transplanted patients. We identified 1 randomised controlled trial (RCT) with 38 transplanted and 45 non-transplanted patients and judged a low risk of bias. We further identified 61 single-arm studies with 256 transplanted patients. Overall survival in the RCT was reported not statistically significantly different between autologous HSCT following HDCT versus SDCT. The HR was $1.26(95 \% \mathrm{Cl} 0.70$ to $2.29 ; \mathrm{p}=0.44)$ and the point estimates at 3 years were $32.7 \%$ vs $49.4 \%$. Data from single-arm studies were used to extract data on adverse events. Treatment-related mortality was reported in $5.1 \%$ (15 of 294 ) transplanted patients.

\footnotetext{
*This article is based on a Cochrane Systematic Review published in the Cochrane Database of Systematic Reviews (CDSR) 2013, Issue 8. Art. No.: CD008216. DOI: 10.1002/14651858.CD008216.pub4 (see http://www. thecochranelibrary.com for information). Cochrane Systematic Reviews are regularly updated as new evidence emerges and in response to feedback, and the CDSR should be consulted for the most recent version of the review.
}

Strengths and limitations of this study

- We conducted a comprehensive literature search and strictly adhered to the projected methodology. The WHO classification of soft tissue sarcomas was adopted and modified to define a clear terminology for the study selection process.

- We judged a low risk of bias for the single identified randomised controlled trial, which may serve as the major relevant evidence.

- Single-arm studies provided some estimation about serious adverse events with transplantation.

- Some treatments were performed 10-20 years ago. Thus, the results may not be applicable to patients who are treated today.

- The included studies report various subtypes of non-rhabdomyosarcoma soft tissue sarcomas, and each tumour type may carry an individual risk profile and, therefore, ideally should be evaluated separately.

Conclusions: Overall survival in patients with locally advanced or metastatic NRSTS was not statistically different after autologous HSCT following HDCT compared with SDCT in a single RCT with a total of 83 patients. No other comparative study was available. The proportion of adverse events among the transplanted patients is not clear.

\section{INTRODUCTION}

Soft tissue sarcomas (STS) are a highly heterogeneous group of rare malignant solid tumours of non-epithelial extraskeletal body tissue and are classified on a histogenetic basis. ${ }^{1}$ The location of the primary tumour can involve any area of the body. ${ }^{2}$ STS can involve any type of tissue and typically affect muscles, tendons, adipose tissue, blood vessels and joints and commonly present as a painless mass. ${ }^{3}$ In this review, we investigated 
non-rhabdomyosarcoma STS (NRSTS) provided that they are categorised as malignant according to the WHO 2002 classification. ${ }^{4}$ In Western countries about four new cases of NRSTS are estimated per 100000 population every year, with the Ewing family of tumours excluded from this statistic. ${ }^{5}$

Surgery is the standard treatment for localised NRSTS and can be curative if distant dissemination is not present. ${ }^{6}{ }^{7}$ Chemotherapy is regarded mainly as a palliative treatment for high-risk patients who are characterised by inoperable, locally advanced and metastatic disease. ${ }^{6}$ Riedel $^{8}$ provides an overview of current systemic therapies and discusses possible novel therapeutic agents and treatment strategies. High-dose chemotherapy (HDCT) has been evaluated as an alternative treatment option for high-risk patients. The rationale for HDCT is that escalating doses of HDCT may increase survival by capturing putatively remnant malignant cells. ${ }^{9}$ The rationale for autologous haematopoietic stem cell transplantation (HSCT) following HDCT is a planned rescue for HDCT-related severe haematological toxicity. ${ }^{9}$ The primary objective of the present systematic review is to evaluate the effectiveness and adverse events of autologous HSCT following HDCT in patients with advanced or metastatic NRSTS.

\section{METHODS}

This article is based on a Cochrane systematic review published in The Cochrane Library. ${ }^{10}$ Publication of this work is in agreement with the policy of The Cochrane Collaboration. ${ }^{11}$ While preparing this systematic review, we endorsed the PRISMA statement, adhered to its principles and conformed to its checklist. ${ }^{12}$

\section{Study inclusion criteria}

We included patients with NRSTS provided that they are categorised as malignant according to the WHO 2013 classification on $\mathrm{STS}^{4}$ as well as malignant haemangiopericytoma and anaplastic sarcoma. We excluded the Ewing family of tumours according to the European Society for Medical Oncology (ESMO) Guidelines Working Group, ${ }^{5}$ chondrosarcomas, osteosarcomas and rhabdomyosarcomas. While writing the Cochrane Review, we referred to the WHO 2002 classification. ${ }^{13}$ For the purpose of the present systematic review, we updated the inclusion criteria and re-evaluated the potentially relevant studies and included the following entities: 'Gastrointestinal Stromal Tumours', 'Malignant peripheral nerve sheath tumour', 'Undifferentiated pleomorphic sarcoma not otherwise specified'. Almost all published studies refer to the 2002 classification. Thus, we continued to include the following entities though they were removed and relocated within the 2013 classification: 'malignant fibrous histiocytoma' (MFH), 'undifferentiated sarcoma', 'unclassified sarcoma', and 'haemangiopericytoma'. Table 1 compares the categories and malignant subtypes of the 2013 versus the 2002 edition of the WHO classification of tumours of soft tissue and indicates which of those are included in the present systematic review. Participants were included regardless of age, severity and clinical stage of disease. Studies were included as long as at least $80 \%$ of patients had NRSTS and received the test intervention. The test intervention was autologous HSCT following HDCT containing stem cells from peripheral blood or bone marrow. The comparator was standarddose chemotherapy (SDCT). The primary outcomes were overall survival and treatment-related mortality (TRM). Secondary outcomes were disease-free survival, progression-free survival, event-free survival, nonhaematological toxicity grades $3-4,{ }^{14}$ secondary malignant neoplasia and health-related quality of life.

\section{Search strategy, selection of studies and data extraction}

We conducted an electronic literature database search in MEDLINE (Ovid), EMBASE (Ovid) and Cochrane Library CENTRAL (Wiley) including articles published from inception to an update search on 12 June 2014. The corresponding search strategies have been published in the corresponding Cochrane Review. ${ }^{10}$ We retrieved all titles and abstracts by electronic searching and downloaded them to the reference management database EndNote V.X3 ${ }^{15}$ We considered studies written in languages other than English. We searched the online registries ${ }^{16} 17$ on 12 June 2014 for additional completed or ongoing studies using the search strategy "sarcoma AND chemotherapy AND transplantation". We searched all retrieved abstracts of annual meetings contained in EMBASE (Ovid). We contacted authors to replenish missing information. All data assessments were performed independently by two independent review authors. We resolved differences by discussion or by appeal to a third review author. We judged whether the autologous HSCT following HDCT could be regarded as a consolidation or a salvage therapy. A consolidation therapy is a treatment that is given after cancer has disappeared following the initial therapy and a salvage therapy is a treatment that is given after the cancer has not responded to other treatments. ${ }^{18}$ We considered a consolidation therapy if the status at transplantation was either a complete or a partial response to the preceding therapy and we considered a salvage therapy if the status was less favourable and in case a relapse was described.

\section{Assessment of risk of bias in included studies}

We have used four criteria from The Cochrane Collaboration's tool for assessing risk of bias in randomised controlled trials (RCTs) ${ }^{19}$ : random sequence generation, allocation concealment, blinding of outcome assessment and selective reporting such as not reporting prespecified outcomes. We extended the Cochrane tool for assessing risk of bias by five criteria that consider non-randomised studies: prospective design, comparable baseline characteristics, assignment of patients to treatment groups, concurrent control, and loss to follow-up. 
Table 1 Inclusion of malignant soft tissue tumours of the WHO classification 2013 vs 2012

\begin{tabular}{|c|c|c|c|c|}
\hline Category & Malignant subtypes & 2013 & 2002 & Inclusion \\
\hline \multirow[t]{7}{*}{ Adipocytic tumours } & & 2013 & 2002 & Included \\
\hline & Dedifferentiated liposarcoma & 2013 & 2002 & Included \\
\hline & Myxoid liposarcoma & 2013 & 2002 & Included \\
\hline & Pleomorphic liposarcoma & 2013 & 2002 & Included \\
\hline & Liposarcoma, not otherwise specified & 2013 & 2002 & Included \\
\hline & Round cell liposarcoma & No & 2002 & Included \\
\hline & Mixed-type liposarcoma & No & 2002 & Included \\
\hline \multirow[t]{6}{*}{ Fibrobastic/myofibroblastic tumours } & & 2013 & 2002 & Included \\
\hline & Adult fibrosarcoma & 2013 & 2002 & Included \\
\hline & Myxofibrosarcoma & 2013 & 2002 & Included \\
\hline & Low-grade fibromyxoid sarcoma & 2013 & 2002 & Included \\
\hline & Sclerosing epitheloid fibrosarcoma & 2013 & 2002 & Included \\
\hline & Malignant haemangiopericytoma & No & No & Included \\
\hline \multirow[t]{4}{*}{ So-called fibrohistiocytic tumours } & & 2013 & 2002 & Included \\
\hline & Pleomorphic 'MFH'/(UPS) & No & 2002 & Included \\
\hline & Giant cell 'MFH'/UPS with giant cells & No & 2002 & Included \\
\hline & Inflammatory 'MFH'/UPS with prominent inflammation & No & 2002 & Included \\
\hline \multirow[t]{2}{*}{ Smooth muscle tumours } & & 2013 & 2002 & Included \\
\hline & Leiomyosarcoma (excluding skin) & 2013 & 2002 & Included \\
\hline Pericytic (perivascular) tumours & & 2013 & 2002 & No \\
\hline \multirow[t]{5}{*}{ Skeletal muscle tumours } & & 2013 & 2002 & No \\
\hline & Embryonal rhabdomyosarcoma & 2013 & 2002 & No \\
\hline & Alveolar rhabdomyosarcoma & 2013 & 2002 & No \\
\hline & Pleomorhic rhabdomyosarcoma & 2013 & 2002 & No \\
\hline & Spindle cell/sclerosing rhabdomyosarcoma & 2013 & No & No \\
\hline \multirow[t]{3}{*}{ Vascular tumours of soft tissue } & & 2013 & 2002 & Included \\
\hline & Epithelioid haemangioendothelioma & 2013 & 2002 & Included \\
\hline & Angiosarcoma of soft tissue & 2013 & 2002 & Included \\
\hline \multirow[t]{3}{*}{ Chondro-osseous tumours } & & 2013 & 2002 & No \\
\hline & Mesenchymal chondrosarcoma & 2013 & 2002 & No \\
\hline & Extraskeletal osteosarcoma & 2013 & 2002 & No \\
\hline \multirow[t]{2}{*}{ Gastrointestinal stromal tumours } & & 2013 & No & Included \\
\hline & Gastrointestinal stromal tumour, malignant & 2013 & No & Included \\
\hline \multirow[t]{6}{*}{ Nerve sheath tumours } & & 2013 & No & Included \\
\hline & Malignant peripheral nerve sheath tumour & 2013 & No & Included \\
\hline & Epithelioid malignant peripheral nerve sheath tumour & 2013 & No & Included \\
\hline & Malignant Triton tumour & 2013 & No & Included \\
\hline & Malignant granular cell tumour & 2013 & No & Included \\
\hline & Ectomesenchymoma & 2013 & No & Included \\
\hline \multirow[t]{12}{*}{ Tumours of uncertain differentiation } & & 2013 & 2002 & Included \\
\hline & Synovial sarcoma NOS & 2013 & 2002 & Included \\
\hline & Epithelioid sarcoma & 2013 & 2002 & Included \\
\hline & Alveolar soft-part sarcoma & 2013 & 2002 & Included \\
\hline & Clear cell sarcoma of soft tissue & 2013 & 2002 & Included \\
\hline & Extraskeletal myxoid chondrosarcoma & 2013 & 2002 & No \\
\hline & Extraskeletal Ewing sarcoma & 2013 & 2002 & No \\
\hline & Desmoplastic small round cell tumour & 2013 & 2002 & Included \\
\hline & Extrarenal rhabdoid tumour & 2013 & 2002 & Included \\
\hline & Neoplasms with perivascular epithelioid cell differentiation & 2013 & 2002 & Included \\
\hline & Intimal sarcoma & 2013 & 2002 & Included \\
\hline & Malignant Mesenchymoma & No & 2002 & Included \\
\hline \multirow{6}{*}{ Undifferentiated/unclassified sarcomas } & & 2013 & No & Included \\
\hline & Undifferentiated spindle cell sarcoma & 2013 & No & Included \\
\hline & UPS & 2013 & No & Included \\
\hline & Undifferentiated round cell sarcoma & 2013 & No & Included \\
\hline & Undifferentiated epithelioid sarcoma & 2013 & No & Included \\
\hline & Undifferentiated sarcoma NOS & 2013 & No & Included \\
\hline
\end{tabular}


We applied The Cochrane Collaboration's criteria for judging risk of bias. ${ }^{20}$

\section{Data synthesis}

We synthesised aggregate data as narrative because data were too scarce to be pooled. Differently from the Cochrane Review, we did not pool time-to-event data on overall survival from studies with individual data. With respect to survival data, we accepted time of diagnosis and beginning of treatment as starting points. We evaluated all 62 studies to search for reports on TRM and tabulated the identified patient data. We evaluated the seven studies reporting aggregate data to search for reports on grade 3-4 non-haematological toxicity in the autologous HSCT following the HDCT arm and tabulated the identified event data.

\section{RESULTS}

Search results

Figure 1 shows the literature search and study flow. We retrieved 1035 records and evaluated 260 full text papers in detail. We included 62 studies with 294 transplanted patients, 1 RCT with 38 transplanted and 45 non-transplanted patients, ${ }^{21} 6$ single-arm studies reporting aggregate case series data, ${ }^{22-27}$ and 55 single-arm studies with individual data. In online registries, we

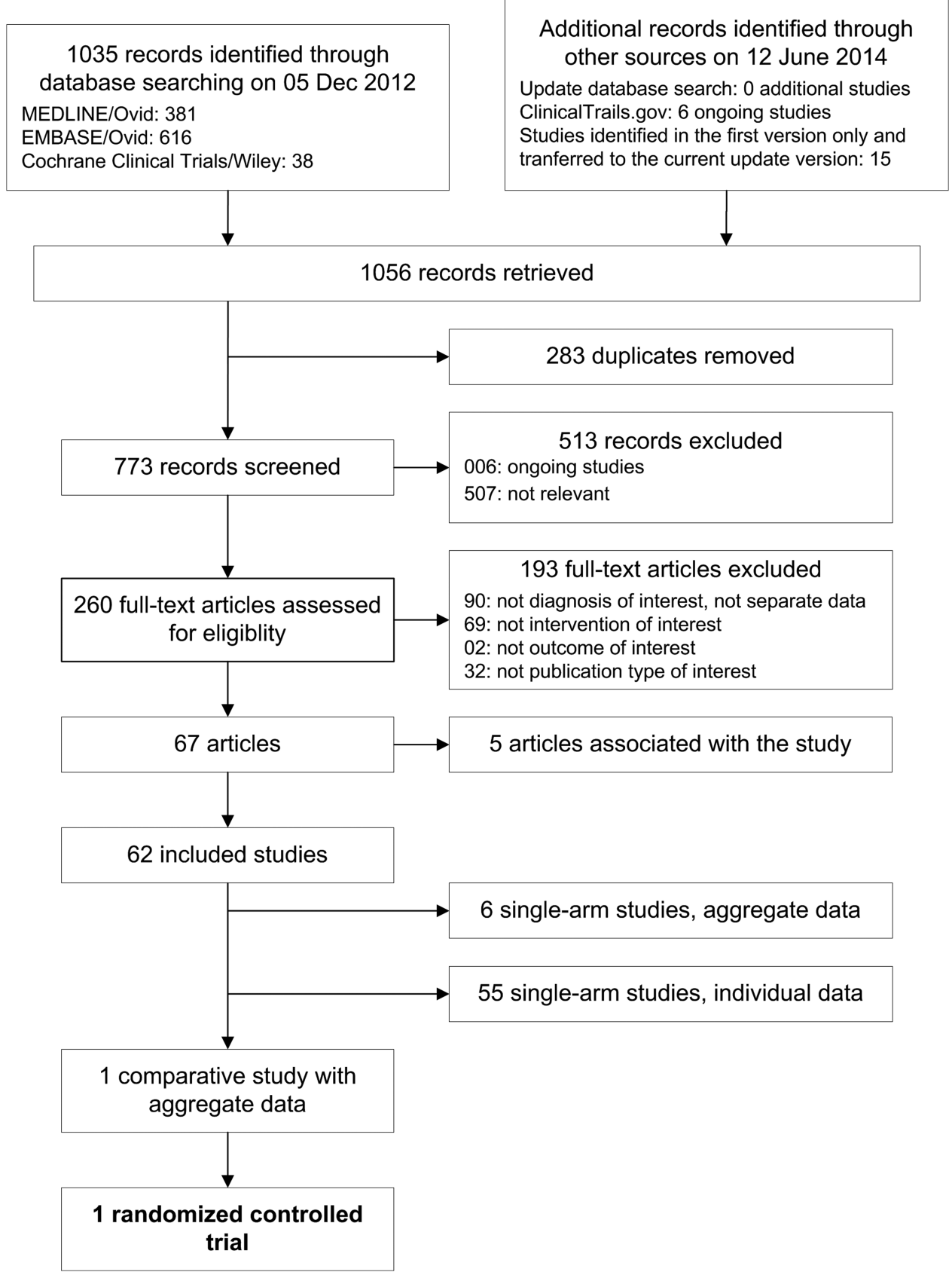

Figure 1 Literature search and study flow. 
Table 2 Characteristics of studies and therapy

\begin{tabular}{|c|c|c|c|c|c|c|}
\hline \multirow[b]{2}{*}{ Study } & \multirow[b]{2}{*}{$\begin{array}{l}\text { Number of } \\
\text { centers } \\
\text { (country) }\end{array}$} & \multirow[b]{2}{*}{$\begin{array}{l}\text { Enrolment; } \\
\text { years }\end{array}$} & \multirow[b]{2}{*}{$\begin{array}{l}\text { Prospective } \\
\text { design }\end{array}$} & \multicolumn{3}{|c|}{ Autologous HSCT following HDCT } \\
\hline & & & & Drugs & $\begin{array}{l}\text { Consolidation } \\
\text { vs salvage vs } \\
\text { NR; N }\end{array}$ & $\begin{array}{l}\text { PBSCT vs BMT } \\
\text { vs NR; N }\end{array}$ \\
\hline \multicolumn{7}{|c|}{ Aggregate comparative data } \\
\hline Bui-Nguyen et $a^{{ }^{1}}$ & 16 (France) & 2000-2008 & Yes & Ca-Et-If & 38 vs 0 vs 0 & 38 vs 0 vs 0 \\
\hline \multicolumn{7}{|c|}{ Aggregate case series data } \\
\hline Bertuzzi et af2 & 1 (Italy) & 1997-2002 & Yes & Me-Mi-Th & 10 vs 0 vs 0 & 10 vs 0 vs 0 \\
\hline Bisogno et $a^{p^{3}}$ & $>1$ (Italy) & 1999-2008 & Yes & Cy-Me-Th & 14 vs 0 vs 0 & 14 vs 0 vs 0 \\
\hline Blay et $a R^{4}$ & 1 (France) & $1988-1994$ & Yes & Ci-Et-If & 0 vs 0 vs 24 & 0 vs 0 vs 24 \\
\hline Bokemeyer et $a^{25}$ & 3 (Germany) & NR & No & Do-If & 16 vs 0 vs 0 & 16 vs 0 vs 0 \\
\hline Cook et $a{ }^{26}$ & 29 (USA) & 1999-2007 & No & Ca-Cy-Et-Me-Th & 0 vs 0 vs 36 & 33 vs 2 vs 1 \\
\hline $\begin{array}{l}\text { Philippe-Chomette } \\
\text { et } a R^{7}\end{array}$ & $>1$ (France) & 1995-2006 & No & Various & 14 vs 0 vs 0 & 0 vs 0 vs 14 \\
\hline \multicolumn{7}{|l|}{ Individual cases data } \\
\hline $\begin{array}{l}55 \text { studies (142 } \\
\text { patients) }\end{array}$ & Various & Various & No & Various & 69 vs 61 vs 12 & 102 vs 21 vs 19 \\
\hline
\end{tabular}

BMT, bone marrow transplant; Ca, carboplatin; Ci, cisplatin; Cy, cyclophosphamide; Do, Doxorubicin; Et, etoposide=Vepesid=VP 16;

HDCT, high-dose chemotherapy; HSCT, autologous haematopoietic stem cell transplantation; If, ifosfamide; Me, melphalan; Mi, mitoxantrone; $\mathrm{N}$, number; NR, information not reported in the article; PBSCT, peripheral blood stem cell transplant; Th, thiotepa.

identified 6 studies with a still pending completion and we did not find additional studies in the update search.

\section{Baseline data}

We provide an overview of the main characteristics of studies and treatment (table 2), of the patients (table 3) and of the frequency of the identified subtypes (table 4). The one RCT was an open, multicenter and randomised phase III study with two parallel treatment groups. ${ }^{21}$ Patients were eligible for randomisation if they had responded to chemotherapy or, for stable disease, if a complete surgical resection of all disease sites could be carried out. The intention-to-treat principle was modified to exclude patients found to be ineligible at a histological review after randomisation. Three of the six single-arm studies reporting aggregate case series data collected the data prospectively ${ }^{22-24}$ and three retrospectively. ${ }^{25-27}$ Data from the remaining 55 singlearm studies were considered for the description of TRM only.

The 62 studies were set in 13 different countries in four different continents. Most of the transplanted patients were studied in France, USA and Germany. We assume that most patients in the studies reporting aggregate case series data received autologous HSCT following HDCT as a consolidation therapy, whereas a considerable number of the individual case data were associated with autologous HSCT following HDCT as a rescue therapy. The majority of all studies used peripheral blood stem cell transplants. Median age varied roughly between 19 and 46 years and there was a male preponderance. Patients had 19 different relevant histological diagnoses. Most patients had desmoplastic small round-cell tumour ( $\mathrm{N}=109$ of 294) followed by the new

Table 3 Characteristics of patients

\begin{tabular}{|c|c|c|c|c|c|c|c|c|}
\hline \multirow[b]{2}{*}{ Study } & \multicolumn{2}{|c|}{$\begin{array}{l}\text { Patients } \\
\text { analysed; N }\end{array}$} & \multirow[b]{2}{*}{ FU } & \multirow[b]{2}{*}{ Subtypes } & \multicolumn{2}{|c|}{ Age; median years (range) } & \multicolumn{2}{|c|}{$\begin{array}{l}\text { Gender; \% } \\
\text { males }\end{array}$} \\
\hline & $\overline{\mathrm{HSCT}}$ & SDCT & & & $\overline{\mathrm{HSCT}}$ & SDCT & $\overline{\text { HSCT }}$ & SDCT \\
\hline \multicolumn{9}{|l|}{ Aggregate comparative data } \\
\hline Bui-Nguyen et $a^{R^{1}}$ & 38 & 45 & 55 (NR) & Various & 46 (19 to 65$)$ & 43 (18 to 65$)$ & 58 & 50 \\
\hline \multicolumn{9}{|l|}{ Aggregate case series data } \\
\hline Bertuzzi et $a^{p^{2}}$ & 10 & NA & 35 (14 to 60$)$ & DSRCT & 29 (NR) & NA & 100 & NA \\
\hline Bisogno et $a^{p^{3}}$ & 14 & NA & $27(\mathrm{NR})$ & DSRCT & 10 (2 to 17$)$ & NA & 93 & NA \\
\hline Blay et $a R^{4}$ & 24 & NA & NR & Various & NR & NA & NR & NA \\
\hline Bokemeyer et a ${ }^{5}$ & 16 & NA & NR & Various & 45 (25 to 57$)$ & NA & NR & NA \\
\hline Cook et $a^{26}$ & 36 & NA & 44 (4 to 89$)$ & DSRCT & 19 (8 to 46$)$ & NA & 80 & NA \\
\hline Philippe-Chomette et $a^{R^{7}}$ & 14 & NA & 23 (9 to 51$)$ & DSRCT & NR (4 to 29$)$ & NA & 86 & NA \\
\hline \multicolumn{9}{|l|}{ Individual cases data } \\
\hline 55 studies & 142 & NA & Various & Various & 25 (1 to 65$)$ & NA & NR & NA \\
\hline
\end{tabular}


Table 4 Frequency of subtypes

\begin{tabular}{lrrc}
\hline Subtype & \multicolumn{1}{c}{ All } & Aggregate & Individual \\
\hline Anaplastic sarcoma & 5 & 0 & 5 \\
Angiosarcoma & 10 & 4 & 6 \\
Clear cell sarcoma & 2 & 1 & 1 \\
Desmoplastic small round & 109 & 74 & 35 \\
cell tumour & & & \\
Epitheloid sarcoma & 2 & 0 & 2 \\
Fibrosarcoma & 6 & 1 & 5 \\
Fibromyosarcoma & 1 & 0 & 1 \\
Leiomyosarcoma & 29 & 14 & 15 \\
Liposarcoma & 15 & 8 & 7 \\
Mesenchymal sarcoma & 2 & 2 & 0 \\
Malignant fibrous & 31 & 13 & 18 \\
histiocytoma & & & \\
Malignant & 8 & 5 & 3 \\
haemamgiopericytoma & & & \\
Malignant peripheral nerve & 4 & 0 & 4 \\
sheath tumour & & & \\
Rhabdoid tumour, & 2 & 0 & 2 \\
extrarenal, extracerebral & & & \\
Spindle cell sarcoma & 1 & 0 & 1 \\
Synovial sarcoma & 32 & 9 & 23 \\
Unclassified sarcoma & 17 & 12 & 5 \\
Undetermined sarcoma & 13 & 4 & 9 \\
Not NRSTS & 5 & 5 & 0 \\
Total number & 294 & 152 & 142 \\
\hline NRSTS, non-rhabdomyosarcoma soft tissue sarcomas. & \\
\hline & & &
\end{tabular}

category of undifferentiated pleomorphic sarcomas $(\mathrm{N}=61)$, which is composed of MFH $(\mathrm{N}=31)$, unclassified sarcoma $(\mathrm{N}=17)$ and undetermined sarcoma $(\mathrm{N}=13)$.

\section{Primary outcome}

Overall survival was not statistically significantly different in the RCT by Bui-Nguyen et $a l^{21}$ between autologous HSCT following HDCT versus SDCT regarding the HR of 1.26 (95\% CI 0.70 to 2.29 ; $\mathrm{p}=0.44$; table 5 ). In this RCT, the point estimates at 3 years were $32.7 \%$ vs $49.4 \%$ based on 8 vs 17 remaining patients at risk. The patients at risk at baseline were 38 vs 45 patients. With respect to the studies reporting aggregate case series data, overall survival for transplanted patients ranged roughly from $20 \%$ to $51 \%$ at 2 years and from $32 \%$ to $40 \%$ at 3 years (table 5). In 10 studies, TRM was associated with 15 of 137 evaluated patients (table 6). Assuming no other TRM in the remaining 157 patients, a risk o procedure-related death might be estimated as $5.1 \%$ (15 of 294).

\section{Secondary outcomes}

Progression-free survival was also not statistically significantly different in the RCT by Bui-Nguyen et $a l^{21}$ between autologous HSCT following HDCT versus SDCT regarding the HR of 1.34 (95\% CI 0.81 to 2.20; $\mathrm{p}=0.25)$. In this RCT, the point estimates at 3 years were $9.3 \%$ vs $21.6 \%$ based on 3 vs 12 remaining patients at risk. The RCT did not report results on disease-free survival and event-free survival. An overview of the number of events of non-haematological toxicity grade $3-4$ is provided in table 7 . In the RCT, 11 events were observed in 38 transplanted patients and 1 event (asthenia) was reported regarding the SDCT arm. In 3 of the studies reporting aggregate case series data, 25 events were observed in 54 transplanted patients in the HSCT arm. The other 3 studies did not report toxicity data. We identified one secondary neoplasia in a single case report. Health-related quality of life scales were not addressed in the included studies.

\section{Data quality}

Clinical heterogeneity was substantial because tumour subdiagnosis varied considerably between patients. Furthermore, tumour stage and metastasis were not reported for all participants. The RCT by Bui-Nguyen $e t a l^{21}$ stands out as it is the only study reporting comparative data. We judged a low risk of bias for this trial for random sequence generation and selective

Table 5 Overall survival in studies reporting aggregate data

\begin{tabular}{|c|c|c|c|c|}
\hline \multirow[b]{2}{*}{ Study } & \multicolumn{4}{|c|}{ Overall survival $(95 \% \mathrm{Cl})$, point estimates } \\
\hline & HSCT at 2 years & HSCT at 3 years & $\begin{array}{l}\text { SDCT at } \\
3 \text { years }\end{array}$ & Statistics \\
\hline \multicolumn{5}{|l|}{ Aggregate comparative data } \\
\hline Bui-Nguyen et a ${ }^{1}$ & & $32.7 \%$ & $49.4 \%$ & $\begin{array}{l}\text { HR } 1.26 \text { (0.70 to } 2.29) \text {, } \\
p=0.44\end{array}$ \\
\hline \multicolumn{5}{|l|}{ Aggregate case series data } \\
\hline Bertuzzi et $a P^{22}$ & $20 \%$ & NR & NA & \\
\hline Bisogno et $a f^{3}$ & $48 \%$ & $38.9 \%$ & NA & \\
\hline Blay et $a f^{4}$ & NR & NR & NÁ & \\
\hline Bokemeyer et a ${ }^{25}$ & $\begin{array}{l}\text { Median } 13 \text { months, } \\
\text { range 3-19 }\end{array}$ & & NA & \\
\hline Cook et $a^{26}$ & NR & $40 \%(24 \%$ to $58 \%)$ & NA & \\
\hline Philippe-Chomette et $a^{P^{7}}$ & $51.4 \%(23.2 \%$ to $79.6 \%)$ & NR & NA & \\
\hline
\end{tabular}


Table 6 Treatment-related mortality in the HSCT arm of all included studies

\begin{tabular}{|c|c|c|}
\hline Study & $\begin{array}{l}\mathrm{N} \text { affected/ } \\
\mathrm{N} \text { evaluated patients }\end{array}$ & Specification \\
\hline \multicolumn{3}{|l|}{ Treatment-related mortality } \\
\hline Bui-Nguyen et $a^{{ }^{1}}$ & $1 / 38$ & Treatment-related leukaemia death 2 years after HSCT \\
\hline Cook et $a{ }^{26}$ & $2 / 36$ & NR \\
\hline Doros et $\left.a\right|^{41}$ & $1 / 1$ & NR \\
\hline Engelhardt et $\left.a\right|^{42}$ & $3 / 24$ & Sepsis ( $N=2)$; pneumonia related to lung metastases $(N=1)$ \\
\hline Kasper et $a{ }^{43}$ & $1 / 14$ & Cardiac arrest of unknown cause \\
\hline Matsuzaki et a/ ${ }^{44}$ & $1 / 1$ & Multiple organ failure \\
\hline Navid et $a{ }^{45}$ & $1 / 2$ & Liver as well as kidney failure \\
\hline Philippe-Chomette et $a{ }^{7}$ & $1 / 14$ & Died of treatment toxicity 12 months after HSCT \\
\hline Saab et $a f^{46}$ & $2 / 4$ & Acute myocardial infarction $(\mathrm{N}=1)$; veno-occlusive disease $(\mathrm{N}=1)$ \\
\hline Slease et $\left.a\right|^{47}$ & $2 / 3$ & Progressive encephalopathy $(\mathrm{N}=1)$; sepsis $(\mathrm{N}=1)$ \\
\hline Total & $15 / 137$ & \\
\hline
\end{tabular}

reporting. However, the trial does have some drawbacks. We judged an unclear risk for allocation concealment because masking of allocation was not described in full detail. We judged a high risk of bias for blinding of outcome assessment because it was not reported for any outcome. The other 61 of 62 studies are single-arm

Table 7 Grade 3-4 NCI-CTCAE non-haematological toxicity in the HSCT arm of studies reporting aggregate case series data

\begin{tabular}{|c|c|c|}
\hline Study & $\begin{array}{l}\mathrm{N} \text { events/ } \\
\mathrm{N} \text { evaluated } \\
\text { patients }\end{array}$ & Specification \\
\hline \multicolumn{3}{|c|}{ Aggregate comparative data } \\
\hline Bui-Nguyen et a ${ }^{11}$ & $11 / 38$ & $\begin{array}{l}\text { Digestive }(\mathrm{N}=8) \\
\text { infection }(\mathrm{N}=2) \\
\text { pain }(\mathrm{N}=1)\end{array}$ \\
\hline \multicolumn{3}{|c|}{ Aggregate case series data } \\
\hline Bertuzzi et $a^{22}$ & NR & NA \\
\hline Bisogno et $a^{23}$ & $1 / 14$ & Mucositis grade 4 \\
\hline Blay et $a^{24}$ & $16 / 24$ & $\begin{array}{l}\text { Neurological grade } \\
4(\mathrm{~N}=1) \text {; lung grade } \\
3 / 4(\mathrm{~N}=2) ; \text { renal } \\
\text { grade } 3 / 4(\mathrm{~N}=5) ; \\
\text { nausea/vomiting } \\
\text { grade } 3 / 4(\mathrm{~N}=8)\end{array}$ \\
\hline Bokemeyer et $a^{25}$ & $8 / 16$ & $\begin{array}{l}\text { No grade 4; } \\
\text { neurological }(\mathrm{N}=1) \text {; } \\
\text { renal }(\mathrm{N}=2) ; \\
\text { infection }(\mathrm{N}=1) \text {; } \\
\text { mucositis }(\mathrm{N}=2) \text {; } \\
\text { nausea/emesis } \\
(\mathrm{N}=2)\end{array}$ \\
\hline Cook et $a^{26}$ & NR & NA \\
\hline $\begin{array}{l}\text { Philippe-Chomette } \\
\text { et } a R^{7}\end{array}$ & NR & NA \\
\hline
\end{tabular}

HSCT, autologous haematopoietic stem cell transplantation following high-dose chemotherapy; N, number; NA, not applicable; $\mathrm{NR}$, not reported; $\mathrm{NCl}-\mathrm{CTCAE}$, National Cancer Institute $(\mathrm{NCl})$ Common Terminology Criteria for Adverse Events (CTCAE) grade III-IV..$^{14}$ studies and are therefore not qualified for assessing a treatment effect.

\section{DISCUSSION}

\section{Outcomes}

We identified one RCT comparing autologous HSCT following HDCT versus SDCT. ${ }^{21}$ The authors reported a difference in overall survival and progression-free survival after the treatment in favour of SDCT but the difference was not statistically significant, respectively. Therefore, there is evidence that patients may not have a better survival after autologous HSCT following HDCT versus SDCT. If at all, this intervention should only be offered after careful consideration and preferably only within a randomised controlled clinical trial. We estimated a TRM of $5.1 \%$, which was somewhat higher than the $2 \%$ reported by others. ${ }^{28}$ Severe toxicity grade 3-4 was sparsely reported. Studies on health-related quality of life were not identified. The frequency of secondary neoplasia in 1 of 294 participants is probably an extreme underestimation of the true frequency due to a relatively short follow-up. The detection of secondary neoplasia depends on a long follow-up and was estimated from $4 \%$ to $6.9 \%$ by others. ${ }^{29} 30$

\section{The WHO 2013 classification}

The WHO recently published the 2013 classification on STS. ${ }^{4}$ The authors inserted the category 'Undifferentiated Pleomorphic Sarcoma Not Otherwise Specified' to lodge those types of STS that are difficult to classify using the current available techniques. ${ }^{31}{ }^{32}$ The authors integrated the terms 'MFH', 'Undifferentiated Sarcoma', and 'Unclassified Sarcoma' into this newly created category. MFH was characterised by an apparent lack of specific differentiation ${ }^{33}$ and it was considered a diagnosis of exclusion. ${ }^{34} \mathrm{MFH}$ was regarded as the most common soft tissue sarcoma of adulthood ${ }^{33}$ and accounted for up to $25 \%$ of patients in clinical trials on soft tissue sarcoma. ${ }^{34}$ In 1992 , Fletcher ${ }^{33}$ reassessed 159 cases with MFH and found 63\% 
(97 of 159) tumours to be specific sarcomas other than MFH. In 2001, Fletcher et $a l^{85}$ confirmed that $84 \%$ (84 of 100) tumours of patients with MFH showed sufficient differentiation to assign them to specific subtypes of STS. The techniques to assess cell differentiation have been substantially improved with the effect that the frequency of the tumour within this category has decreased. ${ }^{36}$ It was supposed that the category of 'Undifferentiated Sarcoma -Otherwise Not Specified' may contain liposarcoma, fibrosarcoma, leiomyosarcoma, rhabdomyosarcoma, other sarcomas, and even carcinomas or lymphomas. ${ }^{36}$ It was estimated that the pathologist might have difficulties in identifying a specific differentiation in $10-15 \%$ of tumours previously called MFH. ${ }^{37}$ The new edition also removed the term 'Haemangiopericytoma'. 31 ' 32 'Gastrointestinal Stromal tumours' and 'Nerve Sheath tumours' were relocated from other classifications and appear for the first time in the soft tissue classifications. ${ }^{31} 32$ Consequently, the term 'Malignant Peripheral Nerve Sheath Tumour' is newly integrated.

\section{Strengths and limitations}

The search strategy had the broad aim of the retrieval of all relevant studies. With respect to historical versions of the Cochrane Review, ${ }^{10}$ we applied two different search strategies and retrieved the same studies with aggregate data but different studies with individual cases data. These results show the substantial difficulty associated with the aim of searching for all published cases. This enterprise appears almost impossible. We adopted the new WHO 2013 classification of STS and made minor modifications to define a clear terminology for the study selection process. The group of NRSTS consists of many subtypes that are difficult to diagnose and separate even today. A considerable number of tumours cannot be clearly assigned to a specific histological category. Thus, we may have tumours with a specific label that might not be true. Otherwise, we may have tumours without a specific label that might belong to a specific category. We excluded studies if the proportion of non-eligible participants were greater or equal to $20 \%$ of the total population to prevent a significant mixture with disease or interventions that are not included in the present review. Authors were contacted to ask for additional data. We judged a low risk of bias for the one identified RCT, which may serve as the major relevant evidence. All other identified studies were single-arm studies that are not helpful in deciding whether autologous HSCT following HDCT for NRSTS is a meaningful treatment option. Therefore, we removed the survival data of studies reporting individual data. Nevertheless, they provided data for estimation about TRM within all included transplanted patients. We also removed data on nonhaematological toxicity of studies reporting individual data because the sparse reporting might have caused a display of non-representative information. The description of consolidation and salvage therapy is based on our judgement and might be judged differently by others. These types of therapy were not precisely reported in most studies. Some treatments were performed 10-20 years ago. Thus, the results may not be applicable to patients who are treated today. All studies report various subtypes of NRSTS and each tumour type may carry an individual risk profile and, therefore, ideally should be evaluated separately. With respect to the individual survival data, follow-up started at different time points, that is, at diagnosis or at start of treatment. The delay between diagnosis and starting HDCT can be considerable.

\section{Other findings and opinions}

We wish to point out that some authors have warned against the use of autologous HSCT following HDCT, indicating the possibility of repositioning of malignant cells. ${ }^{38}$ Others have questioned the use of HDCT with reference to the potential existence of refractory cancer stem cells. ${ }^{9}$ Pedrazzoli et $a l^{39}$ stated that the potential benefit of this treatment option has not been investigated sufficiently in comparative studies. Kasper et at $t^{40}$ concluded that the use of HDCT for locally advanced or metastatic adult (soft tissue and bone) sarcomas still remains highly investigational and should not be performed outside clinical trials. The identified RCT by Bui-Nguyen et $a l^{21}$ provides meaningful comparative data for the first time and its results questions any benefit of the intervention. Finally, we cannot close the chapter as it can be unsecure to rely on a single trial.

\section{CONCLUSION}

Overall survival in patients with locally advanced or metastatic NRSTS was not statistically different after autologous HSCT following HDCT compared with SDCT in a single RCT with a total of 83 patients. No other comparative study was available. A considerable number of patients were not evaluated concerning adverse events, and its proportion among the transplanted patients remains unclear. If this treatment is offered it should only be after careful consideration and only within an RCT.

Acknowledgements The authors thank the Cochrane Gynaecological Cancer Review Group for their assistance during the preparation of the Cochrane Review. The National Institute for Health Research (NIHR) is the largest single funder of the Cochrane Gynaecological Cancer Group.

Contributors FP created the search strategy, analysed the data and wrote the manuscript. AML wrote the manuscript.

Funding Provision of full texts by the University of Cologne, Germany. The publication of this article was supported by the University of Illinois at Chicago (UIC) Research Open Access Article Publishing (ROAAP) Fund.

Competing interests None.

Provenance and peer review Not commissioned; externally peer reviewed. Data sharing statement No additional data are available. 
Open Access This is an Open Access article distributed in accordance with the Creative Commons Attribution Non Commercial (CC BY-NC 3.0) license which permits others to distribute, remix, adapt, build upon this work noncommercially, and license their derivative works on different terms, provided the original work is properly cited and the use is non-commercial. See: http:// creativecommons.org/licenses/by-nc/3.0/

\section{REFERENCES}

1. Weiss SW, Goldblum JR. Enzinger and Weiss's soft tissue tumors. St Louis: Mosby, 2001.

2. Clark MA, Fisher C, Judson I, et al. Soft-tissue sarcomas in adults N Engl J Med 2005;353:701-11.

3. Sondak VK, Chang AE. Clinical evaluation and treatment of soft tissue tumors. In: Weiss SW, Goldblum JR, eds. Enzinger and Weiss's soft tissue tumors. St Louis: Mosby, 2001:21-44.

4. Fletcher CDM, Bridge JA, Hogendoorn PCW, et al. WHO Classification of tumours of soft tissue and bone. 4th edn. Lyon: International Agency for Research on Cancer (IARC), 2013.

5. ESMO/European Sarcoma Network Working Group. Soft tissue and visceral sarcomas: ESMO Clinical Practice Guidelines for diagnosis, treatment and follow-up. Ann Oncol 2012;23(Suppl 7):vii92-9.

6. Casali PG, Blay JY. Soft tissue sarcomas: ESMO Clinical Recommendations for diagnosis, treatment and follow-up. Ann Oncol 2010;21(Suppl 5):v198-203.

7. Kotilingam D, Lev DC, Lazar AJ, et al. Staging soft tissue sarcoma: evolution and change. CA Cancer J Clin 2006:56:282-91.

8. Riedel RF. Systemic therapy for advanced soft tissue sarcomas: highlighting novel therapies and treatment approaches. Cancer 2012;118:1474-85.

9. Banna GL, Simonelli M, Santoro A. High-dose chemotherapy followed by autologous hematopoietic stem-cell transplantation for the treatment of solid tumors in adults: a critical review. Curr Stem Cell Res Ther 2007;2:65-82.

10. Peinemann F, Smith LA, Bartel C. Autologous hematopoietic stem cell transplantation following high dose chemotherapy for non-rhabdomyosarcoma soft tissue sarcomas. Cochrane Database Syst Rev 2013;8:CD008216.

11. Cochrane. The Cochrane Policy Manual [updated 14 April 2011]. Oxford: The Cochrane Collaboration, 2011.

12. Moher D, Liberati A, Tetzlaff J, et al. Preferred reporting items for systematic reviews and meta-analyses: the PRISMA statement. PLoS Med 2009;6:e1000097.

13. Fletcher CDM, Unni KK, Mertens F. Pathology and genetics of tumours of soft tissue and bone. Lyon: IARC Press, 2002.

14. NCl. Common Terminology Criteria for Adverse Events (CTCAE) and Common Toxicity Criteria (CTC). Secondary Common Terminology Criteria for Adverse Events (CTCAE) and Common Toxicity Criteria (CTC). 2009. http://ctep.cancer.gov/ protocolDevelopment/electronic_applications/ctc.htm

15. EndNote Version X3 [program]. New York City: Thomson Reuters, 2013.

16. National Library of Medicine (NLM). ClinicalTrials.gov. Bethesda: National Institutes of Health (NIH), 2013.

17. International Clinical Trials Registry Platform (ICTRP). ICTRP Search Platform. Geneva: WHO World Health Organization, 2013.

18. $\mathrm{NCl}$. NCl dictionary of cancer terms. Bethesda: National Cancer Institute, 2014.

19. Higgins JPT, Altman DG, Sterne JAC. Table 8.5.a The Cochrane Collaboration's tool for assessing risk of bias. Chapter 8: assessing risk of bias in included studies. In: Higgins JPT, Green S, eds. Cochrane Handbook for Systematic Reviews of Interventions Version 510 [updated March 2011] The Cochrane Collaboration, 2011. http://wwwcochrane-handbookorg. Chichester: John Wiley \& Sons, Ltd, 2011.

20. Higgins JPT, Altman DG, Sterne JAC. Table 8.5.d Criteria for judging risk of bias in the 'Risk of bias' assessment tool. Chapter 8 : assessing risk of bias in included studies. In: Higgins JPT, Green S eds. Cochrane Handbook for Systematic Reviews of Interventions Version 510 [updated March 2011] The Cochrane Collaboration. http://wwwcochrane-handbookorg. Chichester: John Wiley \& Sons, Ltd, 2011.

21. Bui-Nguyen B, Ray-Coquard I, Chevreau C, et al. High-dose chemotherapy consolidation for chemosensitive advanced soft tissue sarcoma patients: an open-label, randomized controlled trial. Ann Oncol 2012;23:777-84.

22. Bertuzzi A, Castagna L, Quagliuolo V, et al. Prospective study of high-dose chemotherapy and autologous peripheral stem cell transplantation in adult patients with advanced desmoplastic small round-cell tumour. Br J Cancer 2003;89:1159-61.
23. Bisogno G, Ferrari A, Rosolen A, et al. Sequential intensified chemotherapy with stem cell rescue for children and adolescents with desmoplastic small round-cell tumor. Bone Marrow Transplant 2010;45:907-11.

24. Blay JY, Bouhour D, Ray-Coquard I, et al. High-dose chemotherapy with autologous hematopoietic stem-cell transplantation for advanced soft tissue sarcoma in adults. $J$ Clin Oncol 2000;18:3643-50.

25. Bokemeyer C, Franzke A, Hartmann JT, et al. A phase I/II study of sequential, dose-escalated, high dose ifosfamide plus doxorubicin with peripheral blood stem cell support for the treatment of patients with advanced soft tissue sarcomas. Cancer 1997:80:1221-7.

26. Cook RJ, Wang Z, Arora M, et al. Clinical outcomes of patients with desmoplastic small round cell tumor of the peritoneum undergoing autologous HCT: a CIBMTR retrospective analysis. Bone Marrow Transplant 2012;47:1455-8.

27. Philippe-Chomette P, Kabbara N, Andre N, et al. Desmoplastic smal round cell tumors with EWS-WT1 fusion transcript in children and young adults. Pediatr Blood Cancer 2012;58:891-7.

28. Rosti G, Ferrante P, Ledermann J, et al. High-dose chemotherapy for solid tumors: results of the EBMT. Crit Rev Oncol Hematol 2002;41:129-40.

29. Neglia JP, Friedman DL, Yasui Y, et al. Second malignant neoplasms in five-year survivors of childhood cancer: childhood cancer survivor study. J Natl Cancer Inst 2001;93:618-29.

30. Baker KS, DeFor TE, Burns LJ, et al. New malignancies after blood or marrow stem-cell transplantation in children and adults: incidence and risk factors. J Clin Oncol 2003;21:1352-8.

31. Fletcher CD. The evolving classification of soft tissue tumours-an update based on the new 2013 WHO classification. Histopathology 2014;64:2-11.

32. Doyle LA. Sarcoma classification: an update based on the 2013 World Health Organization Classification of tumors of soft tissue and bone. Cancer 2014;120:1763-74.

33. Fletcher CD. Pleomorphic malignant fibrous histiocytoma: fact or fiction? A critical reappraisal based on 159 tumors diagnosed as pleomorphic sarcoma. Am J Surg Pathol 1992;16:213-28.

34. Matushansky I, Charytonowicz E, Mills J, et al. MFH classification: differentiating undifferentiated pleomorphic sarcoma in the 21st Century. Expert Rev Anticancer Ther 2009;9:1135-44.

35. Fletcher CD, Gustafson P, Rydholm A, et al. Clinicopathologic re-evaluation of 100 malignant fibrous histiocytomas: prognostic relevance of subclassification. J Clin Oncol 2001;19:3045-50.

36. Kelleher FC, Viterbo A. Histologic and genetic advances in refining the diagnosis of "undifferentiated pleomorphic sarcoma". Cancers 2013;5:218-33.

37. ACS. Sarcoma: adult soft tissue cancer. Atlanta: American Cancer Society, 2013

38. Woods WG. Myeloablative therapy followed by stem cell rescue for pediatric solid tumors: a non-transplanter's perspective. Cancer Res Ther Control 1999;9:95-9.

39. Pedrazzoli P, Ledermann JA, Lotz JP, et al. High dose chemotherapy with autologous hematopoietic stem cell support for solid tumors other than breast cancer in adults. Ann Oncol 2006:17:1479-88.

40. Kasper $B, H o A D$, Egerer $G$. Is there an indication for high-dose chemotherapy in the treatment of bone and soft-tissue sarcoma? Oncology 2005;68:115-21.

41. Doros L, Kaste SC, Rodriguez-Galindo C. Sister Mary Joseph's nodule as presenting sign of a desmoplastic small round cell tumor. Pediatr Blood Cancer 2008;50:388-90.

42. Engelhardt M, Zeiser R, lhorst G, et al. High-dose chemotherapy and autologous peripheral blood stem cell transplantation in adult patients with high-risk or advanced Ewing and soft tissue sarcoma. $J$ Cancer Res Clin Oncol 2007;133:1-11.

43. Kasper B, Dietrich S, Mechtersheimer G, et al. Large institutional experience with dose-intensive chemotherapy and stem cell support in the management of sarcoma patients. Oncology 2007;73: 58-64.

44. Matsuzaki A, Suminoe A, Hattori $\mathrm{H}$, et al. Immunotherapy with autologous dendritic cells and tumor-specific synthetic peptides for synovial sarcoma. J Pediatr Hematol Oncol 2002;24:220-3.

45. Navid F, Santana VM, Billups CA, et al. Concomitant administration of vincristine, doxorubicin, cyclophosphamide, ifosfamide, and etoposide for high-risk sarcomas. Cancer 2006;106:1846-56.

46. Saab R, Khoury JD, Krasin M, et al. Desmoplastic small round cell tumor in childhood: the St. Jude Children's Research Hospital experience. Pediatr Blood Cancer 2007(3):274-9.

47. Slease RB, Benear JB, Selby GB, et al. High-dose combination alkylating agent therapy with autologous bone marrow rescue for refractory solid tumors. J Clin Oncol 1988;6:1314-20. 